\title{
The Variation of Interpersonal Meaning Breadth of Bilingual Text "Seribu Kunang-kunang di Manhattan by Umar Khayam"
}

\author{
Eka Yunita Liambo \\ Universitas Negeri Yogyakarta, Yogyakarta, Indonesia
}

\begin{tabular}{l} 
Article Info \\
\hline Article history: \\
Submitted Dec 27, 2017 \\
Revised May 05, 2018 \\
Accepted Aug 23, 2018 \\
Published November 21, 2018
\end{tabular}

Keywords:

bilingual

breadth meaning

interpersonal

translation

variation of meaning

\begin{abstract}
The process of meaning realization to the target language may involve the change of meaning. This change leads to the variation of meaning depth, breadth, and height. This is caused by the differences of linguistic features between the target language and source language. Therefore, the difficulties of finding equivalent words in target language may force translators to use other words which do not have the exactly similar meaning. However, this becomes a phenomenon in translation studies. This research aims to know the variation of interpersonal meaning breadth of a bilingual text. The primary data of this research is the sentences of first bilingual text taken from Seribu Kunang-Kunang di Manhattan translated into A Thousand Fireflies in Manhattan. There were 281 sentences are analysed. The result shows that those sentences found to have different variations. The most frequently variations found in this short story are the first variations in which element functions in the source text and target text have one difference. First variation has $28,82 \%$ then followed by zero variation with $23,48 \%$. Whereas other sentences is classified as the second, third, fourth, fifth and sixth variation of interpersonal meaning breadth with percentage of $18,14 \%$, $4,62 \%, 3,20 \%, 14,23 \%$ and $7,47 \%$. These variations occurring in the first bilingual text Seribu Kunang-Kunang di Manhattan translated into A Thousand Fireflies in Manhattan seems to be done to maintain the correspondence in the target language.
\end{abstract}

\section{Corresponding Author:}

Eka Yunita Liambo, Universitas Negeri Yogyakarta, Yogyakarta, Indonesia

Jl. Colombo No 1, Karangmalang, Caturtunggal, Depok, Sleman, Yogyakarta Indonesia.

Email: ekaliambo@gmail.com

\section{INTRODUCTION}

Translation has played a role in civilization and the development of the entire cultural and intellectual life of mankind for a long time. Abbasi (2012) clearly says that translation plays an important role to expand a culture from certain place widespread. Translation performs as a bridge to convey any types of languages especially those that share similarities that take into consideration the characteistics of linguistics and cultural forms around the world.

Furthermore, the advance of technology and culture is closely tied to the world of translation because all the periods of the historical revival of nations once studied begin with translation. As an example, a country that does not belong to developed country, knows the science from a developed country through translation, is introduced with various perspectives on to modernization and intellectual development. So that the country can finally follow the developed country. 
Indeed, translation is the activity of expressing messages from source language (SL) to target language (TL). In conveying the message from SL to TL there should not be any changes of message even a little. What a deep structure says in SL should be transfered into TL completely. As Nida and Taber (1982) assert that translating belongs to the reproducing message from a language to another language by considerating the equivalence of the TL. It means that traslation does not cover the changing of meaning. Yet, it is an activity to convey meaning in one language to another language by finding the equivalence of $\mathrm{TL}$.

Translation is not just an activity of transforming the original text in one language into text equivalent to the language of other countries, but also a semiotic communication that realizes the meaning and form of the source text to the target text. The meaning or message contained in a text must be retold into another text. Meaning is the first step in translation. With the commodity tangible message or meaning, translation is nothing but a form of communication involving semiotic systems that always operate in context. Attempts to retain meaning are not easy in the process of translation. As a process, communication in translation is to convey meaning through a semiotic system to the reader/listener as a communicator.

A problem that often arises in the translation process is the lack of a word equivalent of SL in TL. In such situations the problem of linguistic and cultural weaknesses starts to arise. This is because each language has its own characteristics and is different from other languages. Differences in the context that always color in the process of language transfer of a text can trigger the emergence of variations. Variations of meaning that can arise can be in the form of addition, subtraction, and omission of elements of meaning sometimes unavoidable. This variation of meaning raises the level or degree of meaning, ie breadth, height, and depth. This fenomena makes the writer interested in conducting simple analysis of translation entitled "The Variation of Interpersonal Meaning Breadth of Bilingual Text Seribu Kunang-Kunang di Manhattan translated into A Thousand Fireflies in Manhattan.

This current research is new in translation study where there are only several researchers who conduct it. This study tries to give new perspective in translation, particularly in translation studies. The old theories stay in the phenomena of meaning shift, while the kinds of the shift and how far the meaning shifted are hardly found in the discussion. Therefore, the focus of the research problem in this study is interpersonal meaning related to the bilingual text. This goal of this study is to know how the interpersonal meaning breadth variates in the translation of T1 which is "Seribu Kunang-Kunang di Manhattan" by Umar Khayam and T2 in English translation entitled "A Thousand of Fireflies in Manhattan" by John H. McGlynn.

\section{THEORY AND METHODS}

\section{Definition of Translation}

Translation definitions that are often cited in research study of translation is the definition put forward by Newmark (1988), Catford (1965), Larson (1989), and Bell (1991). Newmark (1988) assigns translation as a process of percepting meaning of one text then reproducing it into another language in the same way that the writer means. While Catford (1965: 1) sees translation as a language operation in terms of changing words rather that changing the meaning of one language to another language.

According to Larson, (1989: 3) translating means a translator studies the grammatical structure, lexicon, communicative situation, and context in terms of culture of the text of SL. Then there is a process of analyzing the text of source language to find its meaning. The final step is to re-reveal the similar meaning by using lexical items and structures in grammar in accordance with the SL and its cultural context. 
Bell (1991: 13) classifies the terms in translatios which are translating, a translation and translation. Explicitly those definitions associate to three different things, namely (1) translating, which is a term that refers to the process and means 'to translate', an activity, not an object; (2) a translation that is the product of translation process in the form of translated text; And (3) translation associating to an abstract idea that delivers an explanation of the translation process and the product of the process.

\section{Type of Translation}

Translation can be divided in various ways depending on who is the theorist. Jacobson $(1959 / 2004)$ says that translation is devided intro three kinds: Intralingual translation, which is the transferring message of a text in the same language; interlingual occurs when someone transfer a message to another language; and intersemiotik, which is verbal interpretation of nonverbal sign systems.

In other way, Newmark (1981) suggests that translation is divided into two categories; semantic translation dan communicative translation. Semantic translation tends to follow the source language. Therefore, it is more complex and more awkward. While communicative translation focuses on meaning transfered. It is usually smoother, simpler, more direct and understandable.

Moreover, Larson (1989) distributes translation into two different kinds. The translation which is loyal to the source language and tries to copy the form of it is called literal translation. While the translation which is based on the meaning and does not pay attention the the original form is called idiomatic translation.

From those definitions above, it can be concluded that generally can be divided only into two major kinds. A translation which are based on meaning is refered to the target language. The translation which copies the form of source text if refered to the source language.

\section{Strategy of Translation}

The theories of translation can be found as a method of a translation, an approach to translation or strategy of translation. Yet, this term 'strategy' refers to the step of translating a small unit of language. Strategy is used to translate word or frase which is the smaller unit of language.

Vinay and Dalbernet (2004) suggets strategies to translate small units in language as direct translation and oblique translation. From those two strategies, there are seven procedures, which are:

1. Borrowing: the source language words is transfered into the target language.

2. Calque: the source language expression is transfered in a literal translation.

3. Literal Translation: word-for-word translation done well when the languages shares the same culture.

4. Transposition: this is a change of one part language without changing the sense.

5. Modulation: this is justified when the translation sounds awkward to the target language although the grammar is correct.

6. Equivalence: a meaning based technique.

7. Adaptation: this involves changing the cultural form when a situation in SL culture does not exist in the target language. 


\section{Meaning}

Every word may contain more than one meaning. There is word found with direct meaning and word with conotative meaning. Words, according to Djajasudarma (2013) have several meanings: narrowed meaning, extended meaning, denotative meaning, conotative meaning and emotive meaning.

1. Narrowed Meaning

Narrowed meaning is the more spesific meaning of the whole utterance. The meaning whose origin is widespread, can become narrow because of the limitations. For example the word food which is a word that has a broad meaning will be limited if it is limited to the word flash: 'flash food'.

\section{Extended Meaning}

The meaning contained in a word is wider than thought. Words that have wide meaning can come from words that have a narrow meaning. Examples of virtus word from Latin is a wide meaning in English language. Words that have wide meaning are used to express common ideas.

3. Denotative Meaning

Denotative or descriptive meaning is the meaning that shows the relationship between concepts and real world. This meaning is also called the direct meaning that refers to a fixed meaning. Examples of comb refers only to one object.

4. Connotative or Emotive Meaning

The connotative meaning or emotive meaning is the unreal meaning of a word. This meaning is usually called the second meaning. This meaning cannot be determined by just looking at the words, but it has to be determined by the context and situation of the text. A concrete example exists in a golden child. The golden child is not a child with golden color or a child made of gold. Yet, the phrase means a beloved child and the like.

Furthermore, Halliday \& Matthiessen (2004) argues that meaning of a language can be divided into three kinds:

1. Ideational Meaning

The ideational meaning relates to the language function to express someone's experience. Halliday \& Matthiessen (2004) states that clauses have meaning as a message that the speakers choose as a foundation of what they will say. The ideational function consists of two sub functions: experiential and logical.

2. Interpersonal Meaning

Interpersonal meanings relate to the function of text as a means of information exchange or interaction. Each text can be analyzed using an interpersonal meaning approach because each text is written with a specific intent and idea by the author.

3. Textual Meaning

Textual meaning of language is associated to the function of a language as a message. According to Halliday \& Matthiessen (2004: 58), a clause has the meaning of representation of several processes from human experiences. This is interpreted as an intrinsic function of the language itself, but at the same time the language's extrinsic function, in the sense that it is related to the contextual domain in which at the clause level the text is embedded, the textual meaning relates to how the intraclauses are arranged to make meaning. 


\section{Translational Semiotic Communication}

According to the theory proposed by Tou (2008: 23), phenomenon of translation is seen as Translational Semiotic Communication (TSC), therefore the translation itself may be defined as metasemiotic phenomena. Translatics views that TSC does not exist clearly but appears (occurs). This opinion explains that TSC will always appear when someone understands something and interprets something. The process of interpretation is then expressed through the denotative system of language semiotics according to contextual or connotative system of language.

Research using this TSC model is to answer the problems that exist and formulated by formulated with the question: how is the linguistic TSC registers behave that are represented by and within the functional variation of semiotics bilingual language, as revealed by and in the units of related phrases occuring in the translated text of the object of research, what factors are driving it so, how it intrinsically effects the involved linguistic texts themselves and extrinsically to the surrounding contexts. Moreover the question arises on how the quality of the text textually and contextually in its links with the significance of functional variation representing the TSC registers of the bilingual language in a translatic perspective, meaning translations as TSC. The last question is TSC as metasemiotics embracing any kind of semiotic complex that may be involved in the translation and tangible process systems and denotative denotation of semiotics can be various forms of lingual, non-lingual or a combination of both.

\section{Method}

This research is descriptive-qualitative method. Analysis model of variation of interpersonal meaning breadth in this study is constructed by referring to the framework's Tou (2008) through several adaptation. The source of the data of this paper is Seribu Kunang-Kunang di Manhattan by Umar Khayam and its translation in English $A$ Thousand Fireflies in Manhattan translated by H. McGlynn. The data of study are variations of translation clauses in the T1 novel (in English) translated into Indonesian (T2). Variations are determined by paying attention to the realization of translation clauses that change or are different from the source clause.

This analysis focuses on the sentence particularly on the number of elements which forms the sentence. The writer looks at whether there is the decrease or increase of the elements. Then, the writer determining the variation of the target sentence by comparing to the source language.

In determining the variation of interpersonal meaning, the writer refers to the target language, the number of element forming the sentences. The parameter used is taken from Christine Dian Permata Sari (2013: 81). The parameter is used to determine the variation of target language by looking at the interpersonal meaning breadth. The parameter adopted is arranged as follow:

1. Zero Varian, if:

a. Both T1 and T2 are simple sentence and both texts have the same number of functional element.

b. Both T1 and T2 are complex sentence and both texts have the same number of functional element.

2. First Varian, if:

a. Both T1 and T2 consist of one simple sentence, yet there is one different functional element in $\mathrm{T} 2$. 
b. Both T1 and T2 consist of one complex sentence, yet there is one different functional element in $\mathrm{T} 2$.

3. Second Varian, if:

a. Both T1 and T2 consist of one simple sentences, yet there are two different functional elements in $\mathrm{T} 2$.

b. Both $\mathrm{T} 1$ and $\mathrm{T} 2$ consist of one complex sentences, yet there are two different functional elements in $\mathrm{T} 2$.

4. Third Varian, if:

a. Both T1 and T2 consist of three simple sentences, yet there are three different functional elements in $\mathrm{T} 2$.

b. T1 consists of simple sentence, T2 is a complex sentence consisting of two simple clause.

c. Both T1 and T2 consist of one complex sentences, yet there are three different functional elements in $\mathrm{T} 2$.

5. Fourth Varian, if:

a. Both T1 and T2 consist of one simple sentences, yet there are four different functional elements in $\mathrm{T} 2$.

b. T1 is a simple sentence, $\mathrm{T} 2$ is a complex sentence.

c. Both T1 and T2 consist of one complex sentences, yet there are four different functional elements in $\mathrm{T} 2$.

d. T1 is a simple sentence, while T2 consists of three simple sentences.

6. Fifth Varian, if:

a. Both T1 and T2 consist of one simple sentences, yet there are five different functional elements in $\mathrm{T} 2$.

b. T1 is a simple sentence, while T2 is a complex sentence consisting of four or more simple sentences.

c. Both T1 and T2 consist of one simple sentences, yet there are five different functional elements in $\mathrm{T} 2$.

d. T1 is a complex sentence, while T2 consists of four or more simple sentences.

7. Sixth Varian, if:

a. T1 is a simple sentence, yet there is no semiotic system in $\mathrm{T} 2$ or not transfered.

b. T1 is a complex sentence, yet there is no semiotic system in T2 or not transfered.

c. T1 is not transferred, yet in T2 there is a simple or complex sentence.

\section{RESULT AND DISCUSSION}

After reading and analyzing the source and target text, it founds that the meaning realization of interpersonal meaning from $\mathrm{T} 1$ to $\mathrm{T} 2$ has lots of variations. The parameter of the variations are focused in the elemens interpersonal meaning forming the sentences. The finding shows that there were 281 sentences in a short story of Seribu Kunang-Kunang di Manhattan. Then, the researcher read and compared the T2 (its translation into English) A Thousand Fireflies 
in Manhattan. After comparing to its translation, the realization of those sentences element is as follows:

Tabel. 1. The Variation of Interpersonal Meaning Breadth of Umar Khayam's Short Story

\begin{tabular}{|c|c|c|c|c|c|c|c|}
\hline Variation & $\mathbf{0}$ & $\mathbf{1}$ & $\mathbf{2}$ & $\mathbf{3}$ & $\mathbf{4}$ & $\mathbf{5}$ & $\mathbf{6}$ \\
\hline Sentence & 66 & 81 & 51 & 13 & 9 & 40 & 21 \\
\hline Precentage & $23,48 \%$ & $28,82 \%$ & $18,14 \%$ & $4,62 \%$ & $3,20 \%$ & $14,23 \%$ & $7,47 \%$ \\
\hline
\end{tabular}

The result of the data above can be seen practically in the form of a chat below:

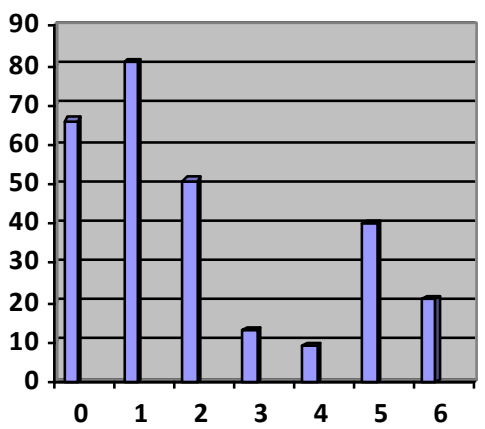

$\square$ Sentence

Figure 1. The Variation of Interpersonal Meaning Breadth in Umar Khayam's Short Strory

From the table and the chart above, it can be concluded that the highest variation of breadth meaning of sentences found in Seribu Kunang-Kunang di Manhattan translated into A Thousand Fireflies in Manhattan is first varian. And the lowest variation is the fourth varian.

\section{Zero Varian}

It states that zero varian is when both $\mathrm{T} 1$ and $\mathrm{T} 2$ are simple sentence and both texts have the same number of functional element or both T1 and T2 are complex sentence and both texts have the same number of functional element. This sentence bellow is the sentence taken from page one:

'kuning keemasan' translated into English as 'golden yellow'

It can be seen that the source text (T1) contains two elements. When it is translated into target text (T2) the elements are still two. This is called as zero varian which means there is no variation in translating the language. Another example is:

'Marno, Sayang.' translated into English as 'Marno, honey.'

This sentence has the same case as the sentence above. It is translated with the same total element forming the sentence. Therefore, these two cases are named zero varian.

Suprisingly, the finding also shows that zero variation can determine the method of translation of the text. Zero variation considering T1 and T2 share the same number and function of the elements is the signal of translation which tends to the source text. It is considered that the translator uses the strategy to translate the text concerning to the source text, centainly the case is called semantic translation (Newmark: 1981) or literal translation (Larson:1989). 


\section{First Varian}

First varian is considered when both $\mathrm{T} 1$ and $\mathrm{T} 2$ consist of one simple sentence, yet there is one different functional element in $\mathrm{T} 2$ or both $\mathrm{T} 1$ and $\mathrm{T} 2$ consist of one complex sentence, yet there is one different functional element in T2. This following example is taken from data number. This varian is shown by data number 2 and number 4 as follows:

\#2 'Marno dengan segelas scotch dan Jane dengan segelas martini' translated into English as 'Marno with his scotch and Jane drinking martini.'

\#4 'Bulan itu Ungu, Marno.' translated into English as 'The moon is purple, Marno.'

The sentences above have different number of element from the translations. For data number two, there are nine (9) elements in T1, while in T2 there are eight (8) elements. The data number four, there are four (4) elements in $\mathrm{T} 1$ whereas in $\mathrm{T} 2$ there are five (5) elements.

\section{Second Varian}

This varian also considers the same criteria as the first varian. However, the different number of elements considered in this varian are two. This varian is shown by the data number 5 and 6. The elaboration given as follows:

\#5 'Kau tetap hendak memaksaku untuk percaya itu?' translated into English as 'Are you still trying to make me believe that?'

\#6 'Ya, tentu saja, Kekasihku.'translated into English as 'Sure honey.'

Both cases above have two different elements. For sentence number 5 there are 7 elements in T1 ad 9 elements in T2. In line with sentence number 5, there are 4 elements in T1 and 2 elements in T2 found in sentence number 6 .

\section{Third Varian}

This varian considers the situation when both $\mathrm{T} 1$ and $\mathrm{T} 2$ consist of one simple sentences, yet there are two different functional elements in T2 or both T1 and T2 consist of one complex sentences, yet there are two different functional elements in T2. There are several cases with this condition such as the data number 60 and 80 described as follows:

\#60 'Ya, aku pernah mendengar orang Eskimo dahulu punya adat-istiadat begitu.'translated into English as 'Someone once told me the Eskimos do.'

\#80 'Dilonggokkannya kepalanya ke bawah dan satu belantara pencakar langit tertidur di bawahnya.' translated into English as 'He looked down at the army of sleeping skyscrapers.'

The data number 60 has 10 elements in $\mathrm{T} 1$ and 7 elements in T2. Whereas the data number 80 has 12 elements in T1 and 9 elements in T2. It means that there are three different elements in each number. Therefore, it is called the third varian.

\section{Fourth Varian}

This varian suggests a condition in which both T1 and T2 consist of three simple sentences, yet there are three different functional elements in T2, T1 consists of simple sentence, $\mathrm{T} 2$ is a complex sentence consisting of two simple clause, or both $\mathrm{T} 1$ and $\mathrm{T} 2$ consist of one complex sentences, yet there are three different functional elements in T2. This case is shown by the data number 48 and number 81 . 
\#48 'Tapi minggu yang lalu kaubilang dia ada di Texas atau di Kansas.' translated into English as 'Last week you said he was in Texas.'

\#81 'Sinar bulan yang lembut itu membuat seakan-akan bangunan-bangunan itu tertidur dalam kedinginan.' translated into English as 'The pale moonlight made the buildings look cold.'

The data number 48 has 12 elements in T1 and 8 elements in T2. Also, the data number 81 has 12 elements in T1 and 8 elements in T2. It means that there are four different elements in each number. Therefore, it is called the fourth varian.

\section{Fifth Varian}

This varian considers the situation when both $\mathrm{T} 1$ and $\mathrm{T} 2$ consist of one simple sentences, yet there are five different functional elements in T2, T1 is a simple sentence, while T2 is a complex sentence consisting of four or more simple sentences, both T1 and T2 consist of one simple sentences, yet there are five different functional elements in T2, or T1 is a complex sentence, while $\mathrm{T} 2$ consists of four or more simple sentences. This varian is shown by the data number 68 and 120.

\#68 'Tetapi bukankah belum tentu Tommy berada di Alaska dan belum tentu pula sekarang Alaska dingin.' translated into English as 'But you don't even know if he is in Alaska.'

\#120 'Marno mengangkat bahunya karena dia tidak tahu apalagi yang mesti diperbuat dengan maaf yang berbalas maaf itu.' translated into English as 'Marno shrugged his shoulders, not knowing what to do with the return sorry.'

The data number 68 has 15 elements in $\mathrm{T} 1$ and 10 elements in T2. While, the data number 120 has 18 elements in $\mathrm{T} 1$ and 13 elements in T2. It means that there are five different elements in each number. Therefore, it is called the fifth varian.

\section{Sixth Varian}

This varian is the last varian considering the situation in which $\mathrm{T} 1$ is a simple sentence, yet there is no semiotic system in $\mathrm{T} 2$ or not transfered, $\mathrm{T} 1$ is a complex sentence, yet there is no semiotic system in T2 or not transferred, or T1 is not transferred, yet in T2 there is a simple or complex sentence. There are several sentence in T1 which are not transferred in T2 such as the data number 73 and 74 viz.:

\#73 'Marno diam sebentar.' not translated into English

\#74 'Kemudian ditepuk-tepuknya tangan Jane.' not translated into English

This omission seems done by the translator because of several reasons that are not surely identified yet. However, the omission in this case can irritate the plot of this short story. It is because some of the omissions are the description of the situation in the story.

\section{CONCLUSION}

The result of variation in the breadth of interpersonal meaning from the highest percentage text occurred at the first variation with $28,82 \%$ followed by the zero variation with $23,48 \%$, the second variation with $18,14 \%$, then fifth variation with $14,23 \%$, the sixth variation at level 7,47\% and the third variation with 4,62\%. While the lowest percentage occurred at the fourth variation level of 3,20\%. Variations in the breadth of interpersonal meanings can be interpreted that most of the functional elements of text one have been represented and realized in text two. This happens because strong intertextuality between the two texts and the translator 
tries to convey all the messages the author wishes to convey, so there is little difference in the number of clauses and functional elements although the grammar of the two texts is essentially different. The clauses in the English text are relatively similar when compared with the Indonesian text which makes the number of functional elements at a level that is not much different and the type of process of the two texts is also almost the same. Moreover, by looking at the percentage of the highest variation that occurs in translation in this, the strategies used by translator in translating this novel is the strategy focusing in the source text.

Unfortunately, this study cannot be separated from the lack. The shortcomings in this study lie in the parameters used to analyse the data. The parameters used by the researchers are the parameters of previous researchers. Therefore, the researcher suggested that if the next researcher wants to conduct the same research, he should consider the parameter that will be used or he can make his own parameter so that the originality of the study is better. Furthermore, this interpersonal meaning study does not only focuses on the breadth of meaning. This study can be developed by increasing the focus of the study such as the depth and the height of meaning translated.

\section{REFERENCES}

Abbasi, G. et al. (2012). Language, Translation and Culture. International Conference on Language, Medias and Culture IPEDR. Vol.33, 83-87.

Bell, R.T. (1991). Translation and translating: theory and practices. London: Longman Group Ltd.

Catford, J. C. (1965). 'A linguistic theory of translation: an essay in applied linguistics'. London Oxford University Press.

Djajasudarma, F.T. (2013). Semantik 2: relasi makna pradigmatik-sintakmatik-derivasional. Bandung: Aditama.

Halliday, M.A.K \& Christian M.I.M. Matthiessen. (2004). An introduction to functional grammar. New York: Oxford University Press Inc.

Jacobson, R. (2004). 'On linguistic aspect of translation' , in Venuti (ed) (2004), pp. 138-43.

Larson, M. L. (1989). Penerjemahan berdasarkan makna: pedoman untuk pemadanan antarbahasa. Jakarta: Arcan.

Newmark, P. (1981). About translation. Clevedon: Multilingual Matters Ltd.

Newmark, P. (1988). 'A text book of translation'. Shanghai Foreign Language Education.

Sari, C. D. P. (2013). Variasi keluasan makna interpersonal teks translasional lintas bahasa novel botchan berbahasa Jepang dan Indonesia. Program Pascasarjana: Universitas Negeri Yogyakarta.

Vinay, J. P. \& Dalbernet, J. (2004). 'A methodology for translation', in Venuti (ed) (2004), pp 128-37.

Tou, A. B. (2008). The Translatics of translation. Journal of modern language, 18, 15-40. 